\title{
Design and Performance Evaluation of a Cooler Refrigerating System Working with Ozone Friendly Refrigerant
}

\author{
Bolaji, B.O ${ }^{1, *}$, Akintaro, A.O ${ }^{2}$, Alamu, O.J ${ }^{3}$ and Olayanju, T.M.A ${ }^{4}$ \\ ${ }^{I}$ Department of Mechanical Engineering, Federal University of Agriculture, P.M.B. 2240, Abeokuta, Nigeria \\ ${ }^{2}$ Department of Mechanical Engineering, Osun State College of Technology, Esa-Oke, Nigeria \\ ${ }^{3}$ Department of Mechanical Engineering, College of Science, Engineering and Technology, Osun State University, \\ P. M.B. 4494, Osogbo, Nigeria \\ ${ }^{4}$ Department of Agricultural Engineering, Federal University of Agriculture, P.M.B. 2240, Abeokuta, Nigeria
}

\begin{abstract}
In this study, a cooler refrigerating system was designed, constructed and tested with various charge quantities of an ozone friendly hydro-fluorocarbon refrigerant (R134a) as working fluid. The results obtained showed that the design temperature and pull-down time set by International Standard Organisation (ISO) for small refrigerator were early achieved with refrigerant charges of 100 and $120 \mathrm{~g}$ than with 60 and $80 \mathrm{~g}$ charges. Approximately the same pull-down time and minimum temperature of $-14^{\circ} \mathrm{C}$ were obtained with refrigerant charges of 100 and $120 \mathrm{~g}$. Discharge pressure is about the same for 60, 80 and $100 \mathrm{~g}$ refrigerant charges, but significant increase in discharge pressure was observed as the refrigerant charge increased to $120 \mathrm{~g}$. The rate of increase in the refrigerating capacity and the COP with respect to evaporator temperature for refrigerant charge of $60 \mathrm{~g}$ to $100 \mathrm{~g}$ are higher than that for refrigerant charge of $120 \mathrm{~g}$. Highest refrigerating capacity and COP of $4.404 \mathrm{~kW}$ and 3.1, respectively, were obtained in the cooler refrigerator with $100 \mathrm{~g}$ charge. Generally, the best performance of the cooler was obtained with refrigerant charge of $100 \mathrm{~g}$ and increase in the charge beyond $100 \mathrm{~g}$ affected the performance of the cooler negatively.
\end{abstract}

Keywords: Design, Performance, Ozone-friendly, Refrigerant charge, Cooler refrigerator.

\section{INTRODUCTION}

Chlorofluorocarbons (CFCs) and hydro-chlorofluorocarbon (HCFCs) are examples of Ozone Depleting Substances (ODS). These chemical have been used for years as refrigerants, solvents and blowing agents. The stable structure of these chemical enables them to attack the Ozone layer. Ozone is a variant of Oxygen and its molecule contains three atoms of Oxygen. Ozone layer surrounds the earth's stratosphere which is about $11 \mathrm{~km}$ above the earth surface. Life on the earth has been safe-guarded for thousands of years because of this life-protecting layer. It acts as shield to protect the earth against the harmful ultraviolet radiation from the sun $[1,2]$.

Ozone layer efficiently screens all the harmful ultraviolet rays of the sun by absorbing most of the dangerous ultraviolet B (UV-B) radiation (Ultra-Violet A is allowed through while ultraviolet $\mathrm{C}$ is captured by oxygen). Since ozone layer is a protector against harmful UV-B radiation, any damage to it could cause considerable harm to the environment and life on earth. Exposure to increased UV-B

*Address correspondence to this author at the Department of Mechanical Engineering, Federal University of Agriculture, P.M.B. 2240, Abeokuta, Nigeria; Tel: +2348185791694; Fax: +23439243045;

E-mail: bobbolaji2007@yahoo.com radiation can lead to incidents of eye damage (such as cataracts, deformation of eye lenses and presbyopia), cause skin cancer, reduce rates of plant growth, upset the balance of ecosystems, and accelerate the risk of disease [3, 4].

$\mathrm{CFC}$ and HCFC escape from refrigeration system into the atmosphere through leakage and during service of the system, thereafter they drift up to the stratosphere were intense UV-C radiation breaks their chemical bonds, releasing chlorine, which stripe an atom from the ozone molecule, reducing it to oxygen molecule. Chlorine acts as a catalyst, which accomplishes this destruction without itself undergoing any permanent changes; therefore it can go on repeating the process. It has been discovered that one chlorine atom can destroy 100,000 ozone molecules. The higher the chlorine content of a compound, the longer will be its impact with the ozone layer $[5,6]$.

CFCs have more chlorine content than HCFCs, therefore, CFCs have higher ozone depleting potential (ODP). It is estimated that CFCs contribute nearly $70 \%$ of man-made ozone depleting chemicals in the atmosphere. Hence, both CFCs and HCFCs are now controlled substances by the Montreal protocol. Production of CFCs was phased out in $1^{\text {st }}$ of January, 1996 and 2010 in the developed and developing countries, respectively. HCFC refrigerants will be phased out by 2020 in developed countries and 2030 in developing countries [6, 7-9]. 
The challenge of replacing R12 with ozone-safe alternatives presents a great dilemma to manufacturers of home refrigerators and freezers since R12 is a very popular working fluid for this application. R12 is used solely in the majority of existing conventional household refrigerator [10]. In compliance with the Clean Air Act Amendments of 1990 and the Montreal Protocol, scientists and researchers are searching for ozone friendly refrigerant to replace R12 in domestic refrigerator and freezers. R134a was the first chlorine-free hydro-fluorocarbon (HFC) refrigerant that was found as a replacement for R12 [11-13].

Thermo-physical properties of R134a are very similar to those of R12 and the refrigerant is also a non-toxic and ozone-friendly refrigerant. Therefore, in the present study, a cooler refrigerating system was designed and constructed using an ozone friendly hydro-fluorocarbon refrigerant (R134a) as working fluid. The system was tested and its performance was evaluated at different operating conditions.

\section{MATERIALS AND METHODS}

\subsection{The Cooling Load Capacity of the Cooler}

The cooling capacity of the cooler is determined by considering the various sources of heat into the refrigerated chamber. It is the summation of the heat, which usually evolves from several different sources. The heat sources considered in the region of this refrigerator using a cooler are:

\section{(a). Transmission Load}

The transmission load is the measure of the heart flows rate by conduction through walls of the refrigerated space from the outside to the inside in unit time. It is obtained as follow:

$\mathrm{q}_{\mathrm{t}}=(\mathrm{A})(\mathrm{U})(\Delta \mathrm{T})$

where, $\mathrm{q}_{\mathrm{t}}=$ the rate of heat transfer $(\mathrm{kJ}) ; \mathrm{A}=$ the outside surface area of the wall $\left(\mathrm{m}^{2}\right) ; \mathrm{U}=$ the overall coefficient of heat transmission $\left(\mathrm{kJ} / \mathrm{m}^{2} \mathrm{~K}\right)$; and $(\Delta \mathrm{T})=$ the temperature different cross the wall $(\mathrm{K})$.

\section{(b). Infiltration Load}

The air change load is the heat flow into the refrigerating space when the cooler is opened. The warm outside air entering the space and the more dense cold air is lost from the refrigerating space through the open door. It is determined as follow:

$\mathrm{q}_{\mathrm{a}}=\mathrm{m}_{\mathrm{a}}\left(\mathrm{h}_{\mathrm{o}}-\mathrm{h}_{\mathrm{i}}\right)$

where, $\mathrm{q}_{\mathrm{a}}=$ air change load $(\mathrm{kJ}) ; \mathrm{m}_{\mathrm{a}}=$ mass of air entering space $(\mathrm{kg} / \mathrm{s}) ; \mathrm{h}_{\mathrm{o}} \quad=$ enthalpy of outside air $(\mathrm{kJ} / \mathrm{kg})$; and $\mathrm{h}_{\mathrm{i}}=$ enthalpy of inside air $(\mathrm{kJ} / \mathrm{kg})$.

\section{(c). Product Load}

The primary sources of refrigeration load from product brought into the refrigerated space are: (i) the heat removal to reduce the product temperature from receiving to storage temperature; (ii) the heat generated by product in storage. The quantity of heat to be removed can be calculated from the knowledge of the product, including its state upon entering the refrigerated space, its final state, mass, specific heat capacity above and below freezing temperature, and its latent heat. The quantity of heat of the product to be stored above it freezing point temperature is given as:

$\mathrm{q}_{\mathrm{pa}}=(\mathrm{m})(\mathrm{c})(\Delta \mathrm{T})$

where, $\mathrm{q}_{\mathrm{pa}}=$ the quantity of heat of the product above freezing point temperature $(\mathrm{kJ}) ; \mathrm{m}=$ mass of product $(\mathrm{kg})$; c $=$ the specific heat capacity $(\mathrm{kJ} / \mathrm{kg} . \mathrm{K})$; and $\Delta \mathrm{T}=$ the change in the product temperature $(\mathrm{K})$.

The specific heat given off by the product in freezing is given as:

$\mathrm{q}_{\mathrm{f}}=\mathrm{mL}_{\mathrm{f}}$

where, $\mathrm{q}_{\mathrm{f}}=$ the quantity of heat in freezing $(\mathrm{kJ})$; and $\mathrm{L}_{\mathrm{f}}=$ latent heat of fusion $(\mathrm{kJ} / \mathrm{kg})$.

The quantity of heat given off by the product in cooling from its freezing temperature to the final storage temperature is obtained as follow:

$\mathrm{q}_{\mathrm{pb}}=(\mathrm{m})(\mathrm{c})(\Delta \mathrm{T})$

where, $\mathrm{q}_{\mathrm{pb}}=$ the quantity of heat of the product below freezing point temperature $(\mathrm{kJ})$.

\section{(d). Light Load}

This is the heat given off by lights installed in the refrigerated space. This contributes to the heat loads of the space and is given as:

$\mathrm{q}_{\mathrm{L}}=$ (Light rating in watt) $\mathrm{x}$ (Time in seconds)

where, $\mathrm{q}_{\mathrm{L}}=$ light load $(\mathrm{kJ})$.

\section{(e). Total Cooling Load}

Total cooling load is the summation of the entire heat load, therefore,

$\mathrm{q}_{\mathrm{TCL}}=\mathrm{q}_{\mathrm{t}}+\mathrm{q}_{\mathrm{a}}+\mathrm{q}_{\mathrm{pa}}+\mathrm{q}_{\mathrm{f}}+\mathrm{q}_{\mathrm{pb}}+\mathrm{q}_{\mathrm{L}}$

where, $\mathrm{q}_{\mathrm{TCL}}=$ total cooling load $(\mathrm{kJ})$. The total cooling load $\left(\mathrm{Q}_{\mathrm{TCL}}\right)$ in watt is obtained as:

$\mathrm{Q}_{\mathrm{TCL}}=\frac{\mathrm{q}_{\mathrm{TCL}}(\mathrm{kJ})}{\text { Time taking (s) }}$

\section{(f). Required Equipment Capacity (REC)}

The cooling load is multiplied by 24 hours and divided by the desired running time in hours to determine the average load. This average load is referred to as Required Equipment Capacity (REC), which is used as a basis for equipment selection.

REC $=\frac{(\text { Total cooling load })(24 \text { hour })}{(\text { Desired running time in hour })}$

\subsection{Equipment Analysis}

For the analysis of the system, the system diagram on $\mathrm{p}-\mathrm{h}$ co-ordinates is used (Fig. 1): process 1-2 represents isentropic compression; process 2-3 represents isobaric cooling and condensing of vapour in condenser; process 3-4 represents isenthalpy pressure throttling; and process 4-1 represents isobaric evaporating of liquid refrigerant. 


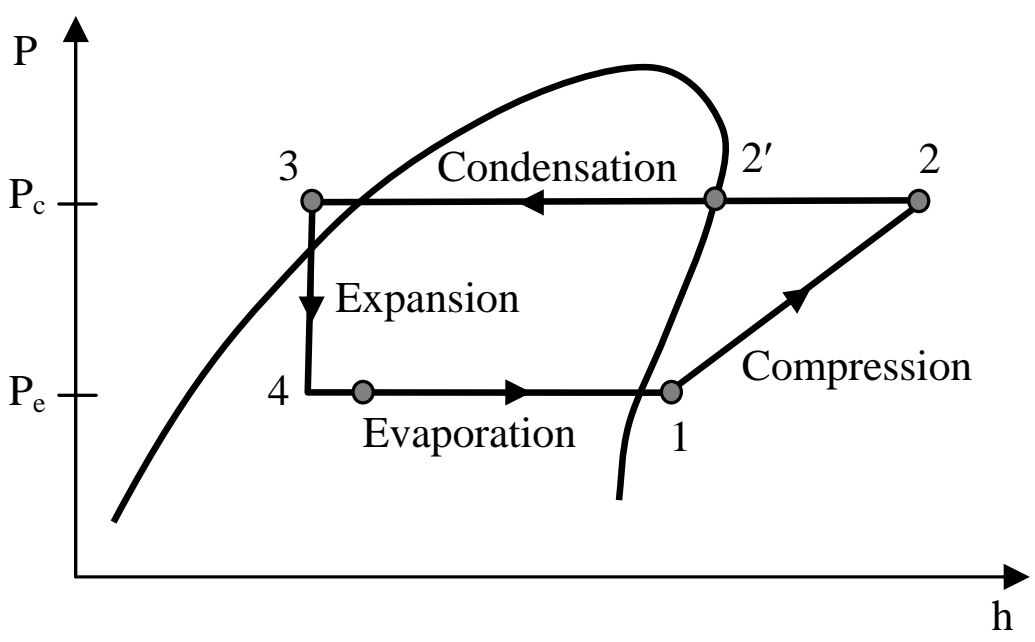

Fig. (1). Vapour compression refrigeration system on p-h diagram.

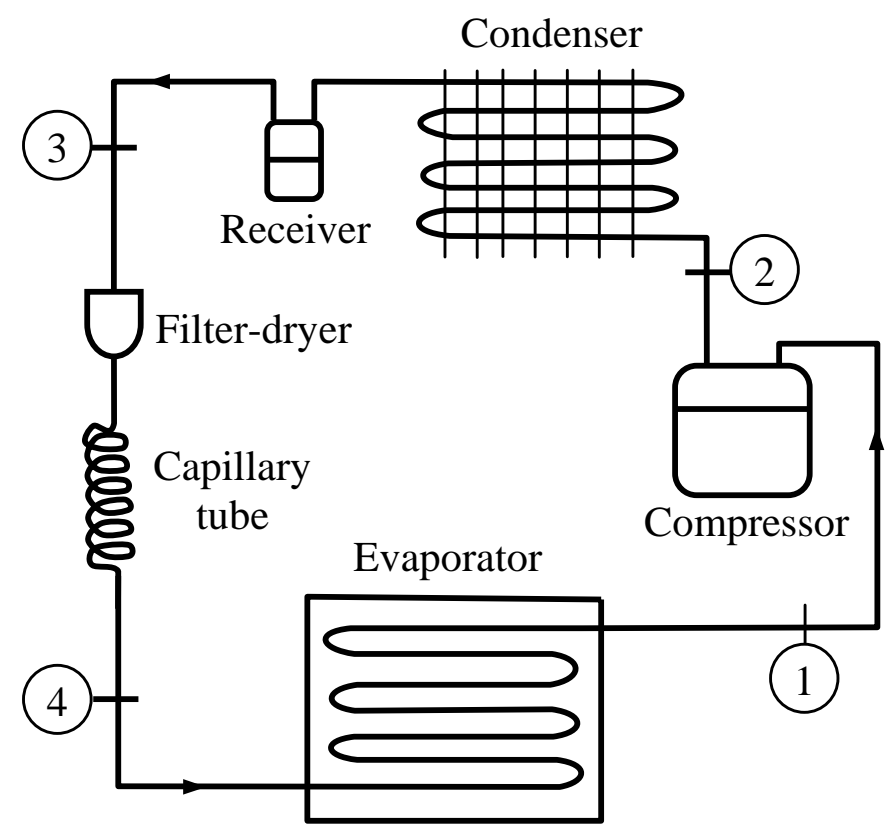

Fig. (2). Schematic diagram of a cooler refrigerating system.

\section{(a). Refrigeration Capacity}

Refrigeration capacity $\left(\mathrm{Q}_{\text {evap }}\right)$ is given as:

$\mathrm{Q}_{\text {evap }}=\dot{m}\left(\mathrm{~h}_{1}-\mathrm{h}_{4}\right)(\mathrm{kW})$

where, $\dot{m}=$ mass flow rate $(\mathrm{kg} / \mathrm{s})$; and $\left(\mathrm{h}_{1}-\mathrm{h}_{4}\right)=$ refrigerating effect of refrigerant $(\mathrm{kJ} / \mathrm{kg})$.

\section{(b). Power Requirement of Compressor}

The compressor power consumption $\left(\dot{W}_{c}\right)$ is given as:

$\dot{\mathrm{W}}_{\mathrm{c}}=\dot{\mathrm{m}}\left(\mathrm{h}_{2}-\mathrm{h}_{1}\right)(\mathrm{kW})$

\section{(c). Determination of Coefficient of Performance (COP)}

From the first law of thermodynamic point of view the measure of performance of the refrigeration cycle is the coefficient of performance (COP) and is the refrigeration effect produced per unit of work required or The compressor power consumption [14]. It is expressed as:

$$
\mathrm{COP}=\frac{\mathrm{Q}_{\text {evap }}}{\dot{\mathrm{W}}_{\mathrm{c}}}
$$

\subsection{Construction of a Cooler Refrigerator}

The cooler works on the principles of vapour compression refrigeration system. The schematic diagram of the refrigeration system is shown in Fig. (2). The system consist the following major components (Fig. 3): compressor, condenser and expansion device, evaporator, and filter-dryer. These are standard components of refrigeration system that are available in the market in their various sizes. They were selected based on the design calculations.

The compressor used for the cooler is a hermetic reciprocating type with power of $0.746 \mathrm{~kW}$ (Fig. 3a). Air cooled wire-and-tube type condenser (Fig. 3b) was used for the cooler. Evaporator of the cooler is a bare plate with inner coil tube for refrigerant flow (Fig. 3c). The evaporator is 


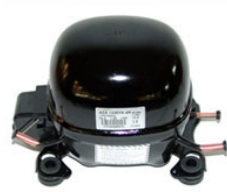

(a)

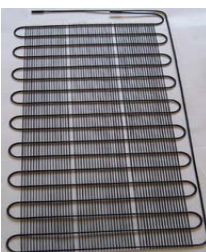

(b) Condenser

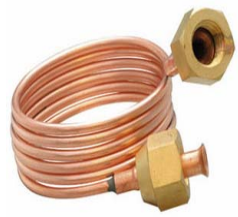

(d) Capillary tube
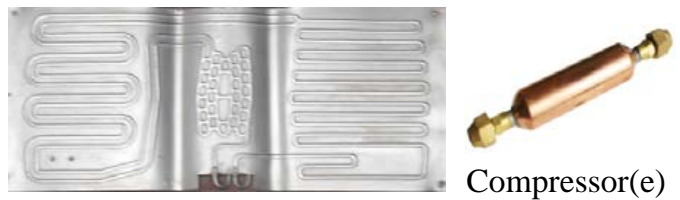

(c) Evaporator

Fig. (3). Standard components of the cooler refrigerator.

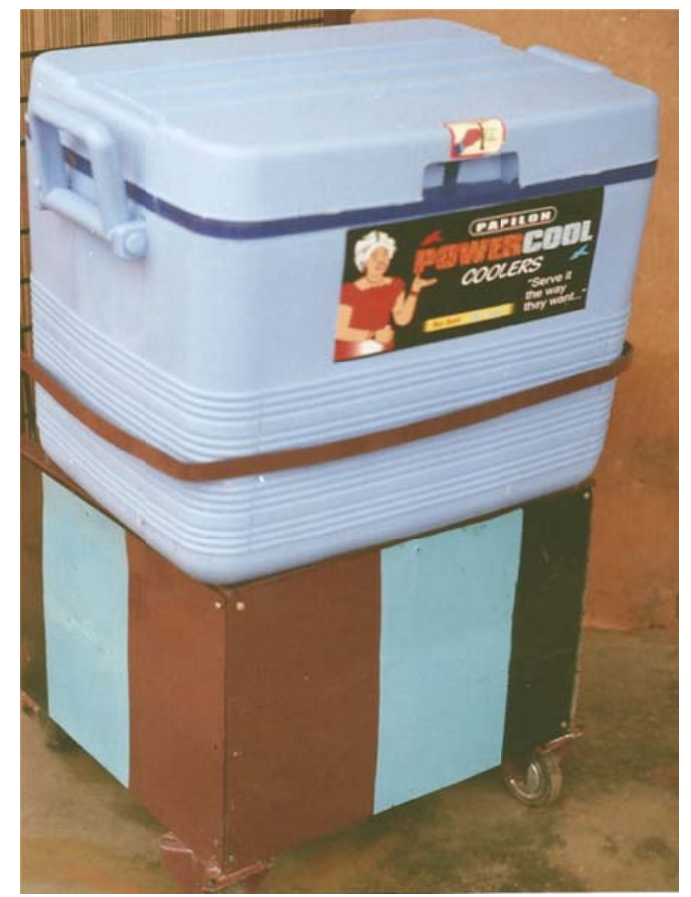

Fig. (4). The general view of the cooler refrigerator.

connected at one end to the capillary tube and at other end to the compressor. A capillary tube is a long, narrow tube of constant diameter. It is a metering device that controls the refrigerant flow by pressure drop. The coiled capillary tube used for the cooler is shown in Fig. (3d). The filter-dryer is a device that removes foreign matter from the refrigerant. The refillable type used for the cooler is shown Fig. (3e). Other components are isolation relay, overload protection and thermostat. All the various parts were assembled together through brazing and soldering, and they are located at the bottom of the cooler, except the evaporator that formed the inner surface of the cooler chamber. Fig. (4) shows the general view of the cooler refrigerator.

\subsection{Experimental Test Procedure}

The refrigerator was instrumented with two pressure gauges (having an accuracy of $\pm 0.25 \%$ of indicated value) at the inlet and outlet of the compressor for measuring the suction and discharge pressure. The temperature of the refrigerant at four different points as indicated in Fig. (2) was measured with copper-constantan thermocouples having an accuracy of $\pm 0.2^{\circ} \mathrm{C}$. Another thermocouple was installed in the cooler cabinet to monitor cooler air temperature. The mass flow rate of the refrigerant was measured by coriolis mass flow meter installed in the liquid line between the dryer and the capillary tube having an accuracy of $\pm 0.2 \%$ of indicated value. Also, the energy consumption of the refrigeration system was measured with energy meter having an accuracy of $\pm 0.25 \%$ of indicated value.

Service ports were installed at the inlet of expansion device and compressor for charging and recovering the refrigerant. The evacuation of moisture in the system was carried out through the service ports with the help of vacuum pump and refrigerant was charged into the refrigerator with the help of charging system. The refrigerator was first charged with $60 \mathrm{~g}$ of R134a and tested at the intended 


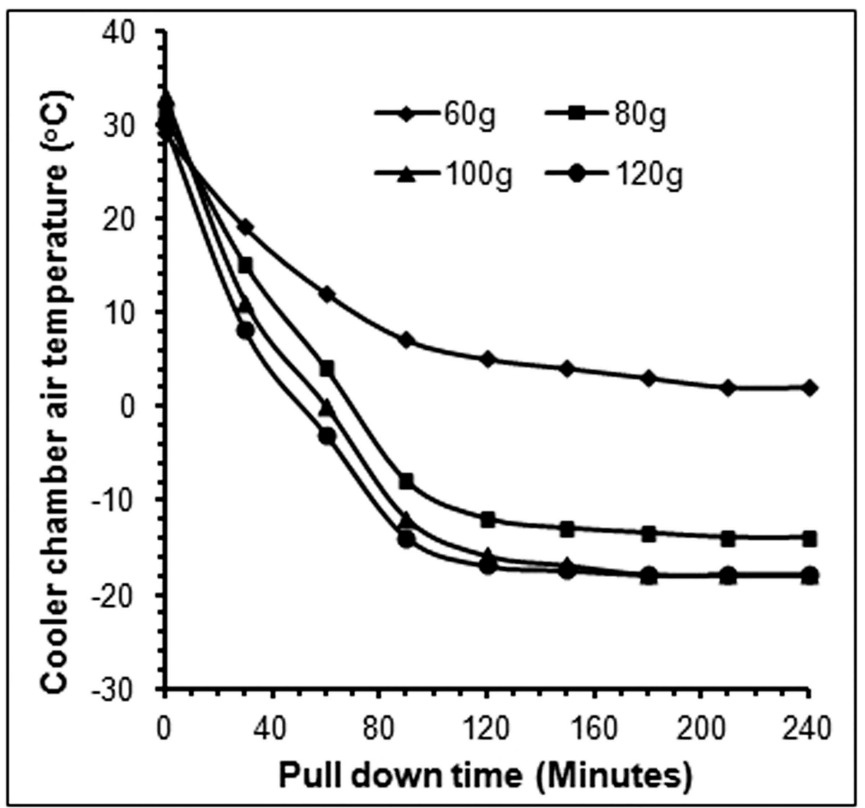

Fig. (5). Pull-down time for various refrigerant charges.

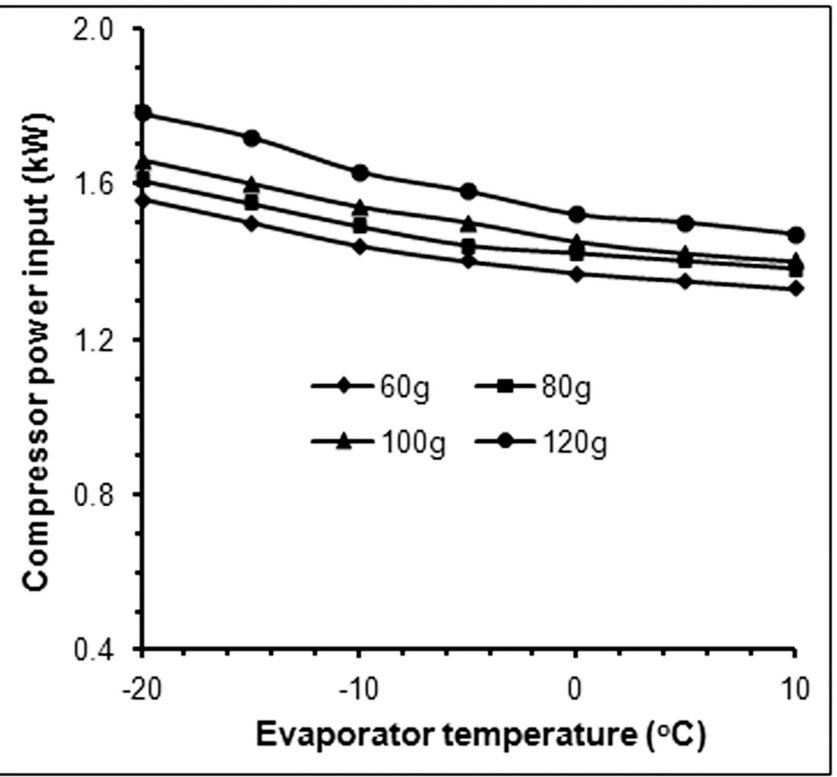

Fig. (6). Variation of compressor power input with evaporator temperature for various refrigerant charges.

various conditions. The tests were carried out in the refrigeration and air-conditioning workshop under prevailing atmospheric condition. Average ambient air temperature of $33^{\circ} \mathrm{C}$ was obtained in the workshop during testing period. The experiment was repeated for $80 \mathrm{~g}, 100 \mathrm{~g}$ and $120 \mathrm{~g}$ of R134a.

\section{RESULTS AND DISCUSSION}

The pull-down time is the time required for changing the cooler chamber air temperature from ambient condition to the desired final temperature $\left(-12^{\circ} \mathrm{C}\right)$ according to International Standard Organisation [15] for the considered refrigerator class. Fig. (5) shows the time taking to achieve low temperature in the cooler chamber for different charges of R134a refrigerant. As shown in the figure, with refrigerant charge of $60 \mathrm{~g}$ the cooler was unable to achieve the desire temperature. Only minimum temperature of $2^{\circ} \mathrm{C}$ was obtained with $60 \mathrm{~g}$ charge at pull-down time of 210 minutes. The pull-down time achieved for 80,100 and $120 \mathrm{~g}$ are approximately 120, 90 and 90 minutes, respectively. The minimum temperatures achieved for 80, 100 and $120 \mathrm{~g}$ charges are $-14,-18$ and $-18^{\circ} \mathrm{C}$, respectively. This shows that the effect of increasing the charge beyond $100 \mathrm{~g}$ is negligible. The design standard set by ISO for this class of refrigerator (temperature of $-12^{\circ} \mathrm{C}$ and pull-down time of 150 minutes) was achieved much earlier with refrigerant charges of 80 to $120 \mathrm{~g}$.

The compressor power consumption is an important criterion to determine the suitability of refrigerant charge in the system. The variation of the compressor power input with evaporator temperature for various refrigerant charges is shown in Fig. (6). The figure shows that the compressor power input decreases as the temperature of the evaporator increases and increases as the refrigerant charge increases. 


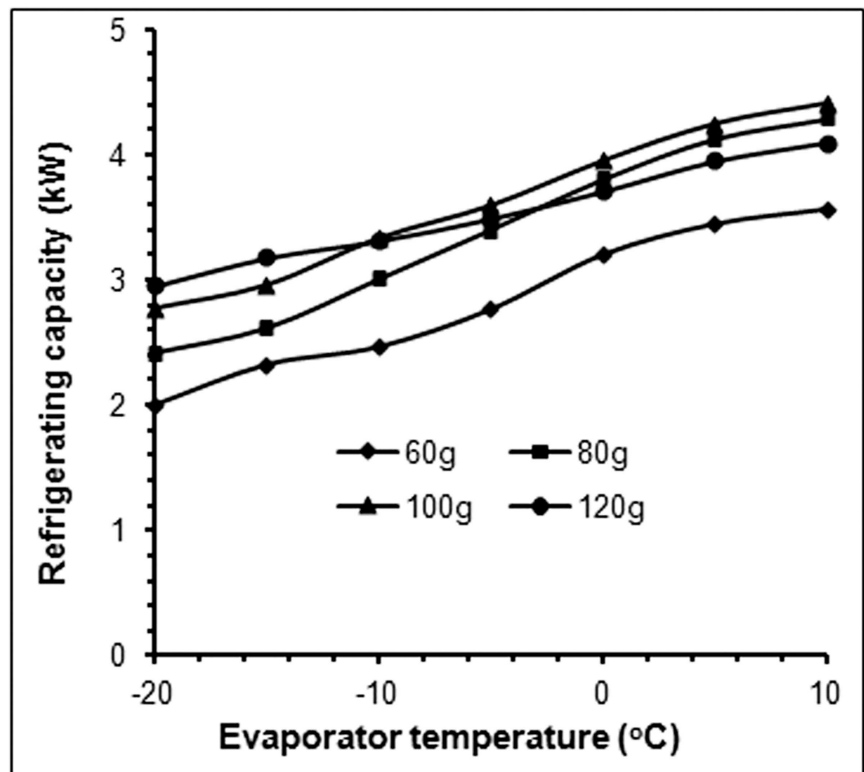

Fig. (7). Variation of refrigerating capacity with evaporator temperature for various refrigerant charges.

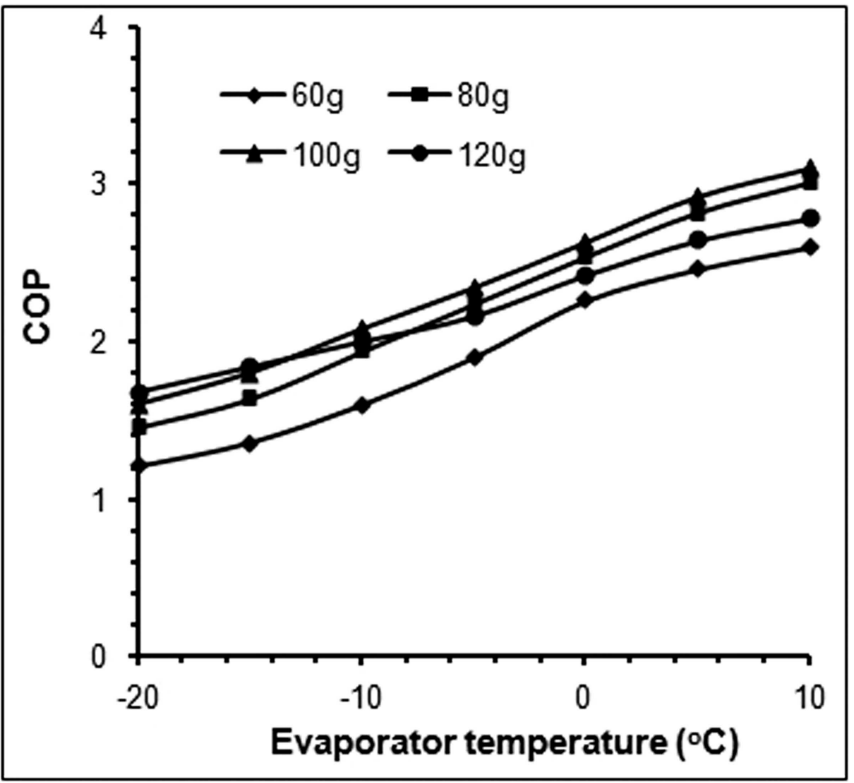

Fig. (8). Variation of coefficient of performance (COP) with evaporator temperature for various refrigerant charges.

This is mainly due to increase in mass flow rate of refrigerant. The average power consumption obtained for the refrigerant charges of 80,100 and $120 \mathrm{~g}$ were $3.4,6.3$ and $12.6 \%$ higher than the value obtained for refrigerant charge of $60 \mathrm{~g}$.

Fig. (7) shows the variation of the refrigerating capacity of the cooler with evaporator temperature for various refrigerant charges. As shown in the figure, refrigerating capacity increases as the evaporator temperature and refrigerant charge increases. This is due to the increase in enthalpy of the refrigerant. A very high enthalpy is desirable since the mass flow rate per unit of capacity is less. When the enthalpy of the refrigerant is high, the efficiency is greatly increased. The rate of increase in the refrigerating capacity with respect to evaporator temperature for refrigerant charge of $60 \mathrm{~g}$ to $100 \mathrm{~g}$ is higher than that for refrigerant charge of $120 \mathrm{~g}$. Increase in refrigerant charge from $60 \mathrm{~g}$ to $80 \mathrm{~g}$ and to $100 \mathrm{~g}$ increases the average refrigerating capacity by 19.6 and $27.8 \%$ above that of $60 \mathrm{~g}$ charge, respectively, while $24.9 \%$ increase was obtained by increasing the refrigerant charge to $120 \mathrm{~g}$. Highest refrigerating capacity of $4.404 \mathrm{~kW}$ was obtained with $100 \mathrm{~g}$ charge.

Fig. (8) shows the variation of the coefficient of performance (COP) of the cooler with evaporator temperature for various refrigerant charges. The COP increases with increase in evaporator temperature for all the refrigerant charges. Fig. (8) clearly shows the effect of refrigerant charges on the system COP; the rate of increase in the COP with respect to evaporator temperature for refrigerant charge of $60 \mathrm{~g}$ to $100 \mathrm{~g}$ is higher than that for refrigerant charge of $120 \mathrm{~g}$. Increase in refrigerant charge from $60 \mathrm{~g}$ to $80 \mathrm{~g}$, and to $100 \mathrm{~g}$ increases the average COP by 16.8 and $23.0 \%$ above that of $60 \mathrm{~g}$ charge, respectively, 


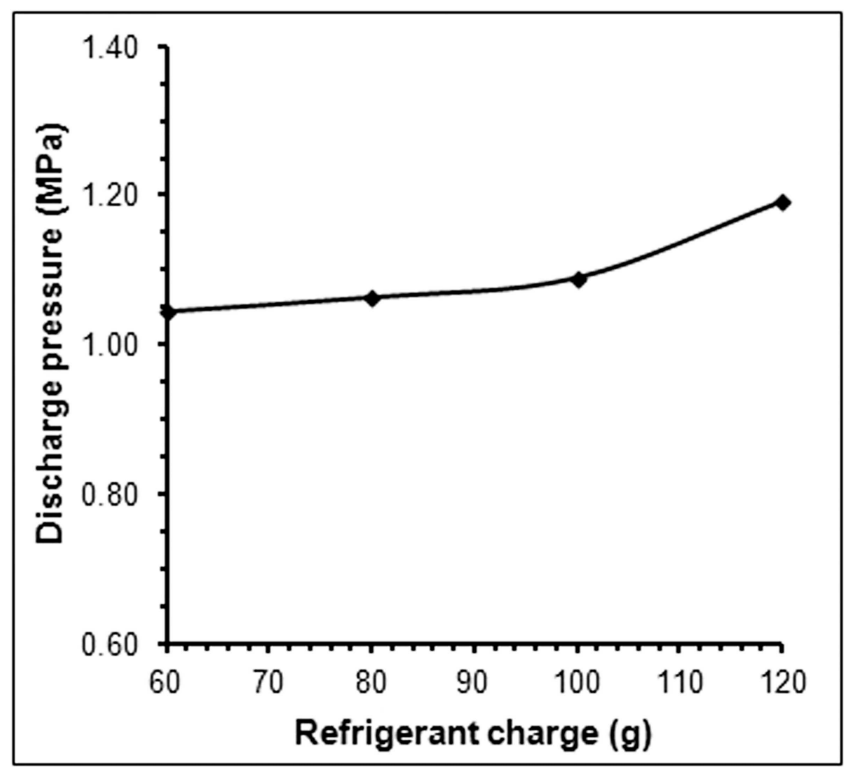

Fig. (9). Discharge pressure versus refrigerant charges.

while $15.9 \%$ increase in average COP was obtained by increasing the refrigerant charge to $120 \mathrm{~g}$. Highest COP of 3.1 was obtained in the cooler refrigerator with $100 \mathrm{~g}$ charge.

Fig. (9) shows the effect of refrigerant charge on the system discharge pressure. The compressor discharge pressure is an important parameter that affects the performance of a refrigerating system. It influences the stability of the lubricants and compressor components. Therefore, refrigerants with lower discharge pressure are more suitable alternative and better than those with high discharge pressure. As shown in Fig. (9), discharge pressure increase slightly as the refrigerant charge increases from 60 to $100 \mathrm{~g}$, while higher increase in discharge pressure was obtained as the refrigerant charge increased to $120 \mathrm{~g}$.

\section{CONCLUSION}

In this study, a cooler refrigerating system was designed, constructed and tested using an ozone friendly hydrofluorocarbon refrigerant (R134a) as working fluid. Based on the experimental results, the following conclusions are drawn:

I. The design temperature and pull-down time set by International Standard Organisation (ISO) for small refrigerator were achieved with 80,100 and $120 \mathrm{~g}$ refrigerant charges, but they were early achieved with 100 and $120 \mathrm{~g}$ charges than with $80 \mathrm{~g}$ charge. Approximately the same pull-down time and minimum temperature of $-14^{\circ} \mathrm{C}$ were obtained with refrigerant charges of 100 and $120 \mathrm{~g}$.

II. The compressor power input increases as the refrigerant charge increases. The average power input obtained for the refrigerant charges of 80,100 and $120 \mathrm{~g}$ were $3.4,6.3$ and $12.6 \%$ higher than the value obtained for refrigerant charge of $60 \mathrm{~g}$.

III. Discharge pressure is about the same for 60,80 and $100 \mathrm{~g}$ refrigerant charges, but significant increase in discharge pressure was observed as the refrigerant charge increased to $120 \mathrm{~g}$.
IV. Increase in refrigerant charge from $60 \mathrm{~g}$ to $80 \mathrm{~g}$, and to $100 \mathrm{~g}$ increases the average refrigerating capacity by 19.6 and $27.8 \%$ above that of $60 \mathrm{~g}$ charge, respectively, while $24.9 \%$ increase was obtained by increasing the refrigerant charge to $120 \mathrm{~g}$. Highest refrigerating capacity of $4.404 \mathrm{~kW}$ was obtained with $100 \mathrm{~g}$ charge.

$\mathrm{V}$. The rate of increase in the COP with respect to evaporator temperature for refrigerant charge of 60 $\mathrm{g}$ to $100 \mathrm{~g}$ is higher than that for refrigerant charge of $120 \mathrm{~g}$. Highest COP of 3.1 was also obtained in the cooler refrigerator with $100 \mathrm{~g}$ charge.

VI. The overall results showed that the cooler performed poorly with refrigerant charge of $60 \mathrm{~g}$ and fairly with refrigerant charge of $80 \mathrm{~g}$. The best performance of the cooler was obtained with refrigerant charge of $100 \mathrm{~g}$ and increase in the charge beyond $100 \mathrm{~g}$ affected the performance of the cooler negatively.

\section{CONFLICT OF INTEREST}

The authors confirm that this article content has no conflicts of interest.

\section{ACKNOWLEDGEMENT}

Declared none.

\section{REFERENCES}

[1] P. M. Midgley, and D. A. Fisher, "The production and release to the atmosphere of chlorodifluoromethane (R22)," Atmospheric Environment, Vol. 28, pp. 162-166, 1994.

[2] B. O. Bolaji, "Investigating the performance of some environmentfriendly refrigerants as alternative to R12 in vapour compression refrigeration system," Ph.D. Thesis, Department of Mechanical Engineering, Federal University of Technology, Akure, Nigeria, 2008.

[3] J. M. Calm, D. J. Wuebbles, and A. K. Jain, "Impacts on Global Ozone and Climate from Use and Emission of 2,2-dichloro1,1,1trifluoroethane (HCFC-123)," Journal of Climatic Change, Vol. 42, pp. 439-474, 1999. 
[4] J. T. McMullan, "Refrigeration and the environment issues and strategies for the future," International Journal of Refrigeration, Vol. 25, pp. 89-99, 2002.

[5] M. S. Bhatti, "A Historical Look at Chlorofluorocarbon Refrigerants," ASHRAE Transactions, Part 1, pp. 1186-1206, 1999.

[6] UNEP, "Handbook for International Treaties for Protection of the Ozone Layers," $6^{\text {th }}$ Ed., United Nation Environment Program, Nairobi, Kenya, 2003.

[7] K. Park, and D. Jung, "Performance of heat pumps charged with R170/R290 mixture," Applied Energy, Vol. 86, pp. 2598-2603, 2009.

[8] B. O. Bolaji, "Performance investigation of ozone-friendly R404A and R507 refrigerants as alternatives to R22 in a window airconditioner," Energy and Buildings, Vol. 43, pp. 3139-3143, 2011.

[9] T. P. Teng, H. E. Mo, H. Lin, Y. H. Tseng, R. H. Liu, and Y. F. Long, "Retrofit assessment of window air conditioner," Applied Thermal Engineering, Vol. 32, pp. 100-107, 2012.
[10] B. O. Bolaji, "Experimental Study of R152a to Replace R12 and R134a in a Domestic Refrigerator," Energy, Vol. 35, pp. 37933798, 2010.

[11] V. S. Lee, and C. C. Su, "Experimental studies of isobutene (R600a) as refrigerant in domestic refrigeration system," Applied Thermal Engineering, Vol. 22, pp. 507-519, 2002.

[12] S. J. Sekhar, D. M. Lal, and S. Renganaraganan, "R134a/R600a/R290 mixture a retrofit for R12 system," International Journal of Refrigeration, Vol. 28, pp. 735-743, 2005.

[13] M. Padilla, R. Revellin, and J. Bonjour, "Exergy analysis of R413A as replacement of R12 in a domestic refrigeration system," Energy Conversion and Management, Vol. 51, pp. 2195-2201, 2010.

[14] R. J. Dossat, and T. J. Horan, "Principles of refrigeration," New Jersey, USA: Prentice-Hall International Inc., 2002.

[15] ISO, "International Standard Organisation," International Standard-8187, Household Refrigerating Applications (Refrigerators/Freezers) Characteristics and Test Methods, 1991.

Received: January 11, 2012

Revised: October 16, 2012

Accepted: October 23, 2012

(C) Bolaji et al.; Licensee Bentham Open.

This is an open access article licensed under the terms of the Creative Commons Attribution Non-Commercial License (http://creativecommons.org/licenses/ by-nc/3.0/) which permits unrestricted, non-commercial use, distribution and reproduction in any medium, provided the work is properly cited. 